\title{
TESTING ALTERNATIVES FOR SALT WEDGE MANAGEMENT IN AN ESTUARY WITH THE USE OF MONITORING AND A MATHEMATICAL MODEL
}

\author{
K.I. HARALAMBIDOU 1 \\ G.K. SYLAIOS ${ }^{1,2}$ \\ V.A. TSIHRINTZIS $1, *$
}

\author{
${ }^{1}$ Democritus University of Thrace, School of Engineering \\ Department of Environmental Engineering \\ Laboratory of Ecological Engineering and Technology \\ 67100 Xanthi, Greece \\ ${ }^{2}$ National Agricultural Research Foundation, Fisheries Research Institute \\ 64007 Nea Peramos, Kavala, Greece
}

Selected from papers presented at the $8^{\text {th }}$ Conference

*to whom all correspondence should be addressed: on Environmental Science and Technology,

8 - 10 September 2003, Lemnos, Greece.

e-mail: tsihrin@otenet.gr

\begin{abstract}
The intrusion of salt wedge in rivers is a natural phenomenon, which occurs in many estuaries. Saline water tends to propagate upstream from the river mouth, due to the limited freshwater and the tidal and density currents developed, resulting in deterioration of water quality in the lower river reach. Several methods to control the salt wedge have been employed, including the construction of inflatable dams or gates. A promising method of control is the use of an air curtain. In this study, a two-dimensional, laterally averaged numerical model has been developed to describe salt wedge intrusion. This model provided necessary hydraulic parameters, which were used in air curtain design theory to evaluate the application of the air curtain method in a particular estuary system. The application takes place in the estuary of Strymon River in Northern Greece, where the limited discharge of freshwater, mainly caused by the construction of Kerkini dam, results in the creation and upstream intrusion of a salt wedge in the summertime, affecting water quality and making water unsuitable for irrigation uses.
\end{abstract}

KEYWORDS: saline intrusion, salt wedge, estuary management, air curtain, numerical modeling, Strymon Estuary.

\section{INTRODUCTION}

Estuaries form the transition zone between the inland freshwater and seawater. Due to their position they are characterized by some unique features and properties, one of which is the intrusion of seawater upstream of the river mouth (whenever river topography is below mean sea level), mainly caused by its higher density. Thus, one of the problems of water management in estuarine areas is the control of salinity, as salinity limits have been assessed for the use of water for various purposes, including irrigation.

Several methods have been proposed to control or prevent salt intrusion. These include, among 
others the construction of small movable dams at the river mouth and the increase of the roughness of the river bottom. One proposed method is the use of an air curtain, which may reduce or prevent totally the intrusion of the wedge. According to this method, compressed air is pumped perpendicularly to the flow from a perforated pipe, placed on the river bed across the channel, forming a vertical air curtain which acts as a wall to the intrusion. The use of the air curtain has been studied through limited laboratory experiments and has been applied in several navigation locks (e.g., Abraham and Burgh, 1964; Raman and Arbuckle, 1989, Hamilton et al., 2001).

This paper presents an application of the air curtain technology in the estuary of Strymon River, Northern Greece, where the limited discharge of freshwater, mainly caused by the upstream construction of Kerkini dam, results in a salt wedge intrusion, affecting water quality and making water unsuitable for irrigation uses. To deal with the problem of the presence of salt wedge in Strymon, an extended study has been undertaken, which includes three major parts: (1) design and application of an extensive field data collection program along the river estuary (Haralambidou et al., 2003a); (2) development of a numerical model, which is used to test alternatives to control the salt wedge intrusion (Haralambidou et al., 2003b); and (3) testing of the effectiveness of the air curtain method with the use of the model (Haralambidou et al., 2003c). In this paper, the numerical model and its use in testing the applicability of the air curtain method in Strymon River Estuary are presented.

\section{MATERIALS AND METHODS Numerical model description}

A two-dimensional, laterally-intregrated, explicit, finite-difference numerical model has been developed to describe the characteristics of the salt wedge intrusion in the estuary of Strymon River. The governing equations of the model are based on the principles of conservation of volume, momentum and mass.

Considering hydrostatic pressure, the Boussinesq approximation, and a Cartesian coordinate system with the origin at the sea surface of the estuary mouth (mean sea level), in which the $\mathrm{x}$-axis is directed upstream and the $\mathrm{z}$-axis is directed upward, the flow governing equations read:
The laterally integrated continuity equation:

$$
\frac{\partial}{\partial x}(B u)+\frac{\partial}{\partial z}(B w)=0
$$

The vertically-integrated continuity equation:

$$
\frac{\partial}{\partial t}\left(B_{\eta} \eta\right)+\frac{\partial}{\partial x} \int_{-d}^{\eta}(u B) d z=0
$$

The momentum conservation equation:

$\frac{\partial}{\partial t}(B u)+\frac{\partial}{\partial x}(B u u)+\frac{\partial}{\partial z}(B u w)-\frac{\partial}{\partial x}\left(B N_{x} \frac{\partial u}{\partial x}\right)-\frac{\partial}{\partial z}\left(B N_{z} \frac{\partial u}{\partial z}\right)+$

$k u|u|\left[1+\left(\frac{\partial B}{\partial z}\right)^{2}\right]^{1 / 2}+B g \frac{\bar{\rho}}{\rho} \frac{\partial \eta}{\partial x}+g B(z+\eta) \frac{1}{\rho} \frac{\partial \bar{\rho}}{\partial x}=0$

where:

$$
\bar{\rho}=\frac{1}{(z+\eta)} \int_{-d}^{\eta} \rho d z
$$

The salt balance equation:

$$
\frac{\partial}{\partial t}(B S)+\frac{\partial}{\partial x}(B u S)+\frac{\partial}{\partial z}(B w S)-
$$

$$
\frac{\partial}{\partial x}\left(B K_{x} \frac{\partial S}{\partial x}\right)-\frac{\partial}{\partial z}\left(B K_{z} \frac{\partial S}{\partial z}\right)=0
$$

The equation of state:

$$
\rho=\rho_{0}(\alpha+\beta S)
$$

where: $x$ and $z=$ horizontal and vertical spatial coordinates, $\mathrm{cm} ; t=$ time, $\mathrm{s} ; \rho(x, z, t)=$ water density, $\mathrm{g} \mathrm{cm}^{-3} ; u(x, z, t)$ and $w(x, z, t)=$ horizontal and vertical laterally-averaged velocities, $\mathrm{cm} / \mathrm{s}$; $B(x, z)=$ channel width, $\mathrm{cm} ; B_{\eta}=$ width at the free surface, $\mathrm{cm} ; g=$ acceleration due to gravity, $\mathrm{cm} \mathrm{s}^{-2} ; \eta(x, t)=$ sea surface displacement, $\mathrm{cm} ; d=$ water depth below mean sea level, cm; $N_{X}$ and $N_{Z}$ $=$ horizontal and vertical eddy viscosity coefficients, $\mathrm{cm}^{2} \mathrm{~s}^{-1} ; K_{X}$ and $K_{Z}=$ horizontal and vertical eddy diffusivity coefficients, $\mathrm{cm}^{2} \mathrm{~s}^{-1} ; k=$ empirically determined drag coefficient, which is expressed as: $k(x)=\frac{g n^{2}}{(8.23)^{2} d^{1 / 3}}$, where $\mathrm{n}$ the Manning roughness coefficient, $\mathrm{s} \mathrm{cm}-1 / 3 ; S(x, z, t)=$ 
salinity, psu; $\rho_{o}=0.9995 \mathrm{~g} \mathrm{~cm}^{-3}$ (density of freshwater); and $\alpha, \beta=$ constants, functions of temperature. For water temperature of $15^{\circ} \mathrm{C}, \alpha=$ 1.00059 and $\beta=7.57 \times 10^{-4}$.

A first order turbulence closure scheme was used for the parameterization of $K_{Z}$ and $N_{Z}$ eddy coefficients, considering their dependence on the local Richardson number $R_{i}$. In the present model, the formulations of $K_{Z}$ and $N_{Z}$ are (Blumberg, 1975, 1977):

$$
\begin{array}{cc}
K_{z}=k_{1}^{2} z^{2}(1-z)^{2}\left|\frac{\partial u}{\partial z}\right|\left(1-\frac{R_{i}}{R_{i c}}\right)^{1 / 2} \\
N_{z}=K_{z}\left(1+R_{i}\right) \quad \text { for } R_{i}<R_{i c} \\
N_{z}=\gamma_{c} K_{z} \quad \text { for } R_{i} \geq R_{i c}
\end{array}
$$

where: $k_{1}=0.5 \mathrm{~cm}^{2} \mathrm{~s}^{-1}, \gamma_{c}=K_{c} / N_{c}$ for the critical condition of stratification $\left(R_{i c}=10, \gamma_{c} \sim 0.05-1.2\right)$ (Yamada, 1975).

Instantaneous values of $K_{Z}$ and $N_{Z}$ are strongly dependent on flow velocity, Manning's roughness coefficient and vertical stratification (Sylaios, 1994; Parissis et al., 2001).

To eliminate non-linear instabilities in the model results, an artificial horizontal viscosity term was introduced (Smagorinsky, 1963). Horizontal eddy viscosity and diffusivity coefficients $K_{X}$ and $N_{X}$ were computed by the model, based upon the formulation of:

$$
K_{x}=N_{x}=\left(\frac{c \Delta x}{\sqrt{2}}\right)^{2}\left|\frac{\partial u}{\partial x}\right|
$$

where: $c$ an adjustable constant and $\Delta x$ the horizontal grid spacing. Therefore, from this artificial viscosity term, wherever the horizontal gradients of velocity are large, the eddy viscosity will become large.

\section{The air curtain method}

Several methods have been proposed to control or prevent intrusion. One of them is the implementation of an air curtain (Abraham and Burgh, 1964; Tuin et al., 1991; Kerstma et al., 1994; Hamilton et al., 2001). Nakai and Arita (2002) presented experimental results on control of salt wedge intrusion in rivers using this method. Their theory is used in this study, based on the following short description.

The salt wedge is influenced by an air curtain in various ways. Nakai and Arita (2002) classified the salt wedge behavior in three types, as illustrated in Figure 1. Under Type I, salt water intrudes into the upstream side over the air curtain along the channel bottom. This type appears when the kinetic energy provided by the buoyancy due to the air curtain is small. Under Type II, saltwater is controlled downstream of the curtain by the strong upward flow. Under Type III, saltwater is also controlled downstream of the air curtain, but some portion enters the upstream side along the channel bottom. Obviously the preferred condition is Type II.

Nakai and Arita (2002) found that external forces dominating the operation of the system are the following three: the buoyancy due to the air curtain, $A$, the intrusion force of the salt wedge, $B$, and the inertial force of the freshwater flow, $R$. All parameters can be written in velocity dimensions (i.e., $\mathrm{m} / \mathrm{s}$ ), as follows (Nakai and Arita, 2002):

$$
\begin{gathered}
A=\left(q_{a} g\right)^{1 / 3} \\
B=\left(g^{\prime} h_{a}\right)^{1 / 2} \\
R=g_{f} / d
\end{gathered}
$$

where: $q_{a}=$ discharge per unit width of air; $\mathrm{g}=$ gravitational acceleration; $\mathrm{g}^{\prime}=$ reduced gravitational acceleration $\left[g^{\prime}=\frac{\left(\rho_{s}-\rho_{f}\right) g}{\rho_{f}}\right] ; \varrho_{s}$ and $\varrho_{f}$ are the densities of saltwater and freshwater, respectively; $h_{a}$ is the salt wedge thickness at the position of the air curtain maker, in the absence of the air curtain; $q_{f}=$ discharge per unit width of freshwater flow; and $d=$ total water depth. The behavior of a salt wedge around an air curtain depends on both ratios $A / B$ and $A / R$, as shown in Figure 2.

\section{Description of the study area}

Salt wedge intrusion is observed at the estuary of Strymon River in Northern Greece. Strymon is a transboundary river, with a total channel length of $315 \mathrm{~km}$ and a total drainage area of $18,329 \mathrm{~km}^{2}$, $39.8 \%$ of which belongs to Greek territory (Hatzigiannakis, 2000). With a NW-SE direction, 


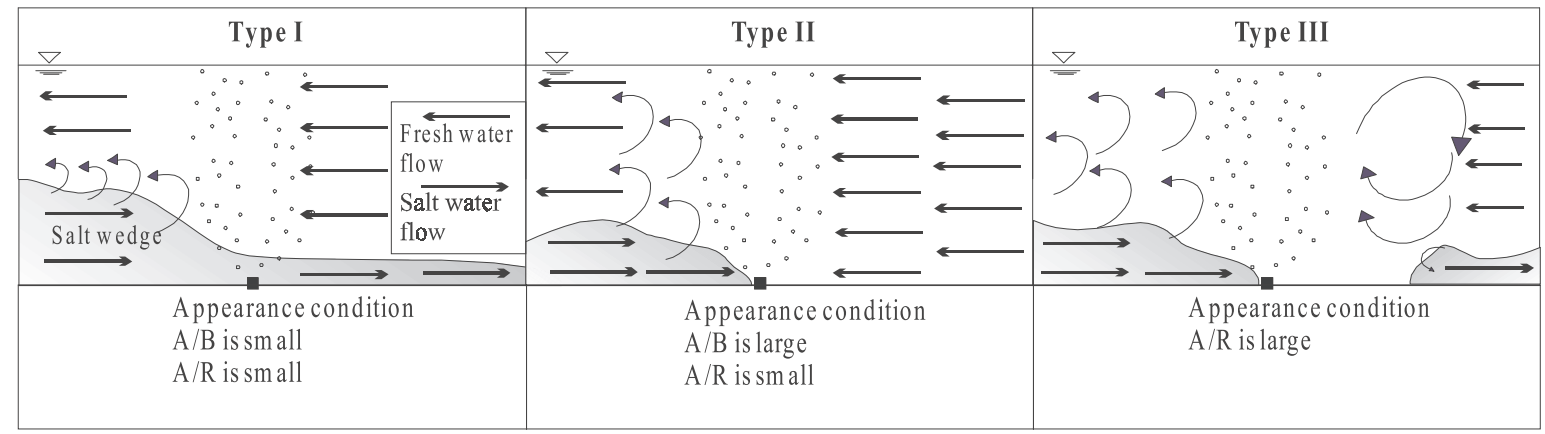

Figure 1. Flow type classification according to Nakai and Arita (2002).

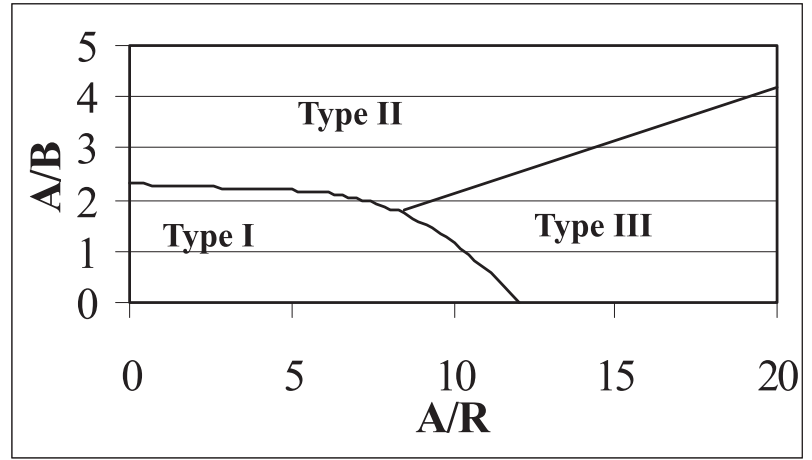

Figure 2. The dependency of the behavior of the salt wedge on ratios $A / B$ and $A / R$ (Nakai and Arita, 2002).

Strymon River enters the Serres drainage area in the Greek territory through the straits of Roupel, passes the Kerkini dam located about $70 \mathrm{~km}$ upstream of the estuary and flows into the Strymonikos gulf in the North Aegean Sea (Figure 3).

The present study involves the estuary system of the river and particularly the area upstream of the river mouth up to the straits of Amphipolis, a distance of approximately $6-8 \mathrm{~km}$. The Strymon Estuary is of the coastal plain type, forced at its mouth by a micro-tidal $\mathrm{M}_{2}$-sinusoidal wave, with a spring range of approximately $0.45 \mathrm{~m}$ and a neap range of $0.10 \mathrm{~m}$. The mean depth of river water in the study area is approximately $3 \mathrm{~m}$, varying in the range $2-5 \mathrm{~m}$, and the mean width is $64 \mathrm{~m}$, varying in the range $40-90 \mathrm{~m}$. An underwater sill also exists at the mouth of the estuary, approximately $200 \mathrm{~m}$ long and 0.2-0.8 $\mathrm{m}$ deep (Vouvalides, 1998). The river discharge varies in the range 0 $120 \mathrm{~m}^{3} \mathrm{~s}^{-1}$ (Hatzigiannakis et al., 2000) due to the presence of the Kerkini dam in the pathway of the river.

The wedge develops mostly in the summer, when there is a great demand for irrigation water for the nearby agricultural fields, as the freshwater discharge from the dam is minimal. A critical point in the estuary is at a distance of approximately $3 \mathrm{~km}$ from the mouth, where a pumping station, which pumps water for irrigation, has been installed. The pump is equipped with a salinity sensor, which interrupts pumping when the water quality is unsuitable for irrigation, i.e., when the salinity is greater than 15 psu. Therefore, in order for the pump to operate, the salt wedge should not extend beyond $3 \mathrm{~km}$ from the mouth.

The field survey was conducted in winter of 2002 and in spring and summer of 2003. Three preliminary sampling campaigns were conducted in winter and spring for the study of seasonal variations (Haralambidou et al., 2003a; 2004). The saline wedge was absent at this period. The summer campaigns were more intense because of the presence of the saline wedge. Five sampling campaigns were made in summer, namely one in June, two in July and two in August. In most cases in the summer the sampling lasted about $12 \mathrm{~h}$. Temperature, conductivity, salinity, $\mathrm{pH}$, dissolved oxygen and velocity were measured along the centerline of the estuary (Figure 3). Data were collected every $0.25 \mathrm{~m}$ from surface to bottom and 


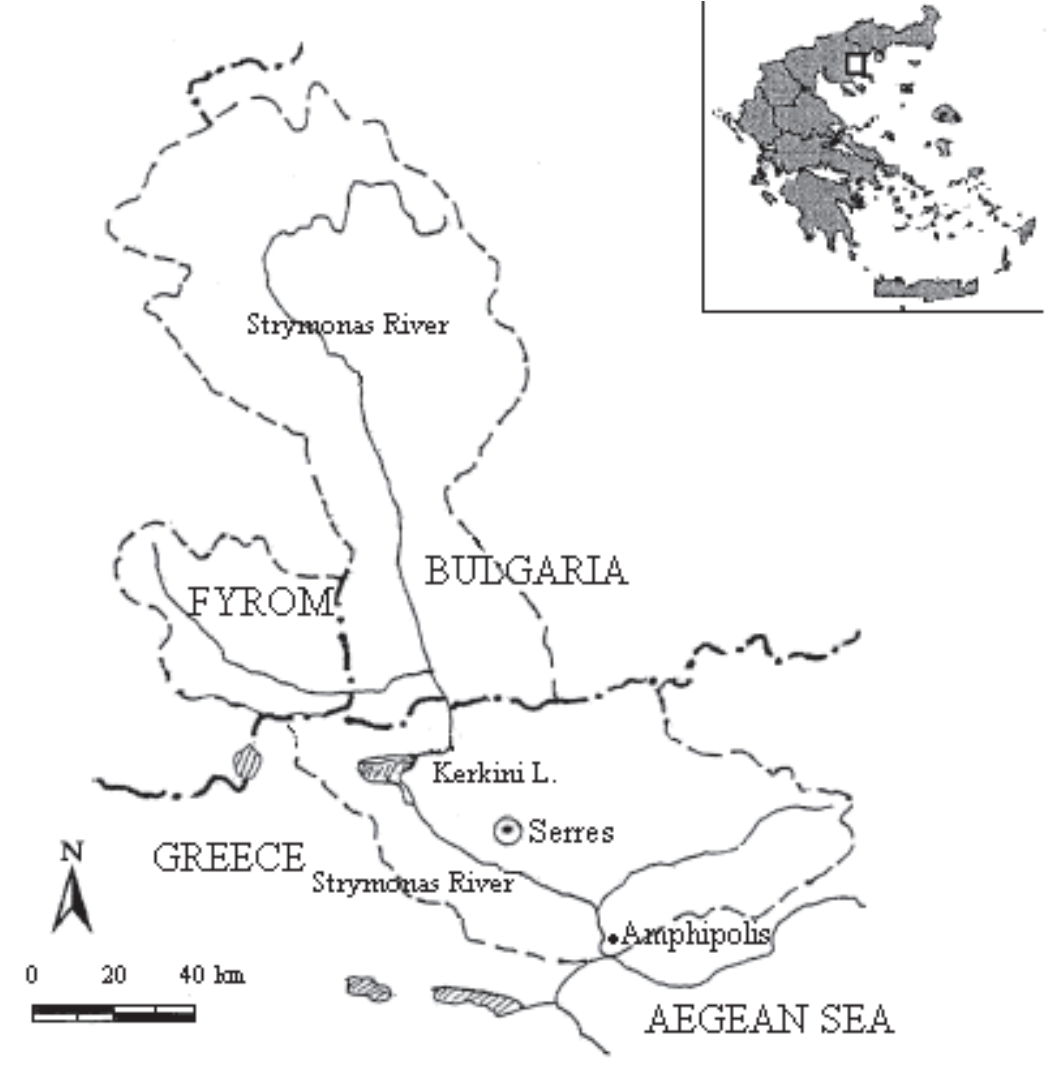

Figure 3. Map of Strymon River system and its location in Greek territory.

profiles of the above mentioned parameters were obtained using conductivity, $\mathrm{pH}$ and dissolved oxygen meters (WTW). The total number of stations along the estuary was variable, as the length of the saline wedge was different based on river discharge and tide.

\section{NUMERICAL EXPERIMENTS AND RESULTS Model results}

Equations (1) to (6) were solved using the method of finite-differences. The computer code was written in FORTRAN 77 and was compiled using PROSPERO FORTRAN. The grid was in the vertical plane, with spacings set at $\Delta x=1000$ $\mathrm{m}$ horizontally and $\Delta z=0.5 \mathrm{~m}$ vertically, and a time step increment of $\Delta t=15 \mathrm{sec}$. A run in time of two tidal periods was found adequate for the tidal regime and the vertical profiles of velocity and salinity to become established. The results of the second period were used in the following analysis. It was assumed that there was no salt flux through the surface or bottom and that there was no wind stress on the surface. The initial distribution of the salinity field was defined by the monitoring surveys with value at the river mouth of approximately 35 psu and value at the head water of 0 psu.

The parameters of $L_{15}$ and $L_{30}$ were introduced to define the salinity intrusion length along the upestuary direction. The parameters $L_{15}$ and $L_{30}$ represent the salt intrusion length defined by the bottom position of the 15 psu and 30 psu-isohalines, respectiverly, measured from the river mouth (Tuin et al., 1991). The model was used to investigate the influence of the river discharge, the tidal amplitude, the bottom Manning's roughness coefficient and the topography of the estuary on the salinity structure in the Strymon Estuary. The conditions simulated by the model are summarized in Table 1. Figure 5 illustrates a representative salinity profile under the typical summer flow condition of $Q=15 \mathrm{~m}^{3} \mathrm{~s}^{-1}$, with a spring tidal 
range of $D E=45 \mathrm{~cm}$ and Manning's roughness coefficient $n=0.050$.

Effect of river discharge: To study the responses of salinity distribution to varying river discharge, the model was run for river discharge values $Q=1 \mathrm{~m}^{3}$ $\mathrm{s}^{-1}$ to $Q=30 \mathrm{~m}^{3} \mathrm{~s}^{-1}$, with tested values of $1,5,15,20$ and $30 \mathrm{~m}^{3} \mathrm{~s}^{-1}$, and with a spring tidal range of $D E=45 \mathrm{~cm}$ and a Manning's roughness coefficient $n=0.050$ (Table 1 ). Figure 6a shows the salinity intrusion lengths $L_{15}$ and $L_{30}$ as function of river discharge, $Q$. It is apparent that the magnitude of the salinity intrusion length depends inversely on the magnitude of the river discharge, as expected. It is also seen that the freshwater discharge is a quite sensitive parameter in controlling salt wedge intrusion.

Effect of tidal amplitude: The model was also run for different tide regimes. The neap tide, the mean and the spring tides have been tested, with amplitudes $D E$ of $10 \mathrm{~cm}, 18 \mathrm{~cm}$ and $45 \mathrm{~cm}$. The river discharge was set to $Q=15 \mathrm{~m}^{3} \mathrm{~s}^{-1}$, and the Manning's roughness coefficient to $n=0.050$ (Table 1). The results are presented in Figure $6 \mathrm{~b}$. It is apparent that there is a nearly exponential increase of the salinity intrusion length with the increase of tidal amplitude. For the given freshwater discharge, it is also seen that the neap tide under these conditions the 30 psu isohaline does not enter the river $\left(L_{30}=0\right)$ but the 15 psu isohaline progresses more than $4 \mathrm{~km}$ up-estuary. Again, the tidal amplitude is a quite sensitive parameter in controlling salt wedge intrusion.

Effect of Manning's roughness coefficient: The effect of varying the Manning's roughness coefficient $n$ was tried by making runs using $n$ values from 0.020 to 0.065 , with tested values of 0.020 , $0.035,0.040,0.050,0.060$ and 0.065 , with constant values of river discharge $\left(Q=15 \mathrm{~m}^{3} \mathrm{~s}^{-1}\right)$ and tidal amplitude $(D E=45 \mathrm{~cm})$ (Table 1$)$. The results are shown in Figure 6c. It is apparent that a small decrease of saline intrusion takes place as the roughness coefficient increases.

Effect of the river mouth topography: The model was run for different widths and underwater sill heights at the mouth. The widths $W$ have been tested in the range from $W=50 \mathrm{~m}$ to $W=80 \mathrm{~m}$, with tested values of 50, 60, 70 and $80 \mathrm{~m}$. In another set of runs, the underwater sill heights at the river mouth $S H$ varied from $S H=0.5 \mathrm{~m}$ to $S H=2 \mathrm{~m}$, with tested values of $0.5,1,1.5$ and $2 \mathrm{~m}$ (i.e., the sill was raised). The parameters of river discharge $\left(Q=15 \mathrm{~m}^{3} \mathrm{~s}^{-1}\right)$ and tidal amplitude $(D E=45 \mathrm{~cm})$ remained constant throughout these tests (Table 1). A small increase in the length of salinity intrusion was observed as the width increased, which was more obvious on the 15 psu-

Table 1. Summary of conditions of numerical model experiments.

\begin{tabular}{|c|c|c|c|c|c|c|}
\hline Parameter & $\begin{array}{c}\text { Typical } \\
\text { Conditions }\end{array}$ & $\begin{array}{c}\text { Case 1: } \\
\text { Effect of } \\
\text { Freshwater } \\
\text { Discharge }\end{array}$ & $\begin{array}{c}\text { Case 2: } \\
\text { Effect of } \\
\text { Tidal } \\
\text { Amplitude }\end{array}$ & $\begin{array}{c}\text { Case 3: } \\
\text { Effect of } \\
\text { Manning's } \\
\text { Roughness } \\
\text { Coefficient }\end{array}$ & $\begin{array}{c}\text { Case 4: } \\
\text { Effect of } \\
\text { Mouth } \\
\text { Width }\end{array}$ & $\begin{array}{c}\text { Case 5: } \\
\text { Effect of } \\
\text { Sill } \\
\text { Height }\end{array}$ \\
\hline $\begin{array}{c}\text { Freshwater } \\
\text { Discharge } \\
\left(\mathrm{m}^{3} \mathrm{~s}^{-1}\right)\end{array}$ & 15 & $\begin{array}{c}\text { Varying: } \\
1 \text { - } 30\end{array}$ & 15 & 15 & 15 & 15 \\
\hline $\begin{array}{l}\text { Tidal } \\
\text { Amplitude } \\
\text { (m) }\end{array}$ & 18 & 45 & $\begin{array}{l}\text { Varying: } \\
10-45\end{array}$ & 45 & 45 & 45 \\
\hline $\begin{array}{l}\text { Manning's } \\
\text { Roughness } \\
\text { Coefficient }\end{array}$ & 0.050 & 0.050 & 0.050 & $\begin{array}{c}\text { Varying: } \\
0.020-0.065\end{array}$ & 0.050 & 0.050 \\
\hline $\begin{array}{c}\text { Mouth } \\
\text { Width (m) }\end{array}$ & 80 & 80 & 80 & 80 & $\begin{array}{c}\text { Varying: } \\
50-80\end{array}$ & 80 \\
\hline $\begin{array}{l}\text { Sill Height } \\
\quad(\mathrm{m})\end{array}$ & 2.5 & 2.5 & 2.5 & 2.5 & 2.5 & $\begin{array}{l}\text { Varying: } \\
0.5-2.0\end{array}$ \\
\hline
\end{tabular}


isohaline than the 30 psu-isohaline. On the contrary, no significant change was observed as the underwater sill height at the mouth rose (Figure $6 \mathrm{~d}, 6 \mathrm{e})$.

\section{Air curtain results}

The model was used to obtain the values of density of saltwater and freshwater for different values of river discharge $Q$, tidal amplitude $D E$, Manning's roughness coefficient $n$, widths $W$ and sill height $\mathrm{SH}$ at the mouth of the estuary. The conditions simulated by the model and tested using the air curtain, are summarized in Table 2. Flow types (i.e., I, II or III according to Figures 3 and 4) for the conditions mentioned above resulted from the calculation of the ratios $A / R$ and $A / B$ (Eqs. 7). Figure 7 presents some of these results based on the number of observations made. The following are observed:

- As the river freshwater discharge increases the flow type moves from Type I to II.

- For the same values of river discharge, an increase in the air flow $q_{a}$ has as a consequence the elimination of Type I condition and the appearance of Type II. Type III appears at minimum tested river discharge of $Q=15 \mathrm{~m}^{3} \mathrm{~s}^{-1}$.

- There is no significant effect on flow type for changes in the Manning's roughness coefficient, sill height at the river mouth and width of the channel. However, there is an impact on the flow type when the discharge of the air increases. In particular for $q_{\mathrm{a}}=0.01 \mathrm{~m}^{3} \mathrm{~s}^{-1} \mathrm{per}$ unit width all conditions of Manning's roughness coefficient tested are of Type I and for $q_{a}$ $=0.05 \mathrm{~m}^{3} \mathrm{~s}^{-1}$ per unit width most conditions are of Type III. Exactly the same happens in the cases of varying sill height and width of the channel.

- In relation to tidal amplitude, the neap tide condition appears to be out of the range of the diagram, whereas the spring tide condition is of Type I and the mean tide condition is of Type II. As $q_{\mathrm{a}}$ rises mean tide condition remains of Type II and spring tide condition moves from Type I to Type III.

\section{PROPOSALS FOR THE MANAGEMENT OF THE SALT WEDGE}

From the sensitivity analysis of the model it is obvious that:
1. River freshwater discharge is the most sensitive parameter. Thus, if no other measures are taken to solve the problem, a minimum constant flow of $30 \mathrm{~m}^{3} \mathrm{~s}^{-1}$ should be negotiated by authorities and be released from Kerkini dam at all times. This flow would keep the 15 psu isohaline downstream of the pumping station even during spring tides.

2. The tidal amplitude is also a very sensitive parameter, affecting salt wedge intrusion.

3. Manning's roughness coefficient has only a minor effect on the propagation of the salt wedge. Thus, roughening the riverbed by installing artificial concrete blocks or dumping rock and crushed stone would be a rather expensive and ineffective solution. This could, however, be done in conjunction with another measure.

4. Reducing the width of the river mouth has some minor impact on the salt wedge propagation. It could be done relatively inexpensively, but since it cannot eliminate totally the problem, it should be done in conjunction with another measure.

5. Raising also the sill height at the mouth did not show to have a significant impact on the propagation of the salt wedge. Furthermore, this measure would create problems with small fishing boats passing through the mouth. Thus, this should not be an option, unless, as mentioned above, the tide is totally blocked, for example, with an inflatable dam.

From the application of the air curtain method it is apparent that:

1. When the river discharge is greater that $\mathrm{Q}=30$ $\mathrm{m}^{3} \mathrm{~s}^{-1}$, a discharge of air $q_{\mathrm{a}}$ of the order of 0.01 $\mathrm{m}^{3} \mathrm{~s}^{-1}$ per unit width is sufficient to produce flow of Type II. On the contrary, for river discharge less that $\mathrm{Q}=30 \mathrm{~m}^{3} \mathrm{~s}^{-1}$ an increase in $q_{\mathrm{a}}$ improves the situation from Type I to Type II.

2. In relation to varying Manning's roughness coefficient and characteristics of the topography of the estuary, an increase in $q_{\mathrm{a}}$ does not alter the type of the flow and is considered to be meaningless.

3. Under spring tide conditions high values of $q_{\mathrm{a}}$ are more effective, as they alter the condition from Type I to Type III. However, under mean tide condition there is no need to alter the $q_{\mathrm{a}}$ value. 
Table 2. Summary of conditions tested using the air curtain method for density of fresh water $\varrho_{f}=1.005396 \mathrm{~g}$ $\mathrm{cm}^{-3}$, total water depth $d=3 \mathrm{~m}$ and testing discharges of air $q_{a}=0.01$ and $0.05 \mathrm{~m}^{3} \mathrm{~s}^{-1}$ per unit width.

\begin{tabular}{|c|c|c|}
\hline Parameter & $q_{f}\left(m^{3} / s\right.$ per unit width $)$ & $\varrho_{s}\left(\mathbf{g} / \mathbf{c m}^{3}\right)$ \\
\hline \multicolumn{3}{|c|}{ River Discharge Q (m³/s) } \\
\hline 15 & 0.229 & 1.0224 \\
\hline 20 & 0.305 & 1.0179 \\
\hline 30 & 0.457 & 1.0098 \\
\hline 40 & 0.610 & 1.0084 \\
\hline 50 & 0.762 & 1.0080 \\
\hline \multicolumn{3}{|c|}{ Tidal Amplitude DE (cm) } \\
\hline 10 & 0.229 & 1.0055 \\
\hline 18 & 0.229 & 1.0101 \\
\hline 45 & 0.229 & 1.0224 \\
\hline \multicolumn{3}{|c|}{ Manning's Roughness Coefficient n } \\
\hline 0.020 & 0.229 & 1.0290 \\
\hline 0.030 & 0.229 & 1.0282 \\
\hline 0.040 & 0.229 & 1.0258 \\
\hline 0.050 & 0.229 & 1.0224 \\
\hline 0.060 & 0.229 & 1.0190 \\
\hline 0.065 & 0.229 & 1.0174 \\
\hline
\end{tabular}

Width of Estuary Mouth W (m)

\begin{tabular}{clc}
\hline 50 & 0.229 & 1.0199 \\
\hline 60 & 0.229 & 1.0218 \\
\hline 70 & 0.229 & 1.0225 \\
\hline 80 & 0.229 & 1.0224 \\
\hline Underwater Sill Height SH (m) & 0.229 & 1.0241 \\
\hline 0.5 & 0.229 & 1.0236 \\
\hline 1.0 & 0.229 & 1.0229 \\
\hline 1.5 & 0.229 & 1.0224
\end{tabular}

$\mathrm{q}_{\mathrm{f}}=$ discharge of freshwater flow per unit width; $\mathrm{Q}_{\mathrm{s}}=$ density of saltwater

\section{CONCLUSIONS}

A two-dimensional, laterally-integrated, explicit finite-difference numerical model was developed to describe salt wedge dynamics in Strymon River estuary. This model was applied successfully and proved to be an effective tool in testing alternative management scenarios for controlling salt wedge intrusion in this estuary. The effect of river freshwater discharge, tidal amplitude, bottom Manning's roughness coefficient, river mouth width and underwater sill height at the river mouth was also studied. Finally, the model provided the required minimum air flow value for air curtain technology application to stop salt wedge upstream progression under given river flow and tide amplitude conditions. 


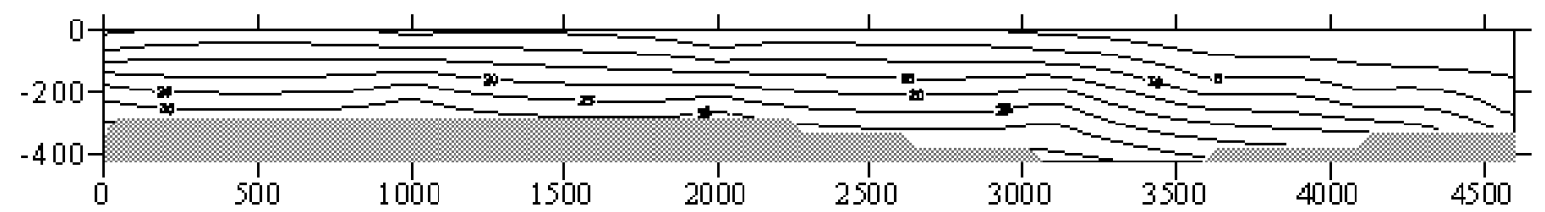

(a)

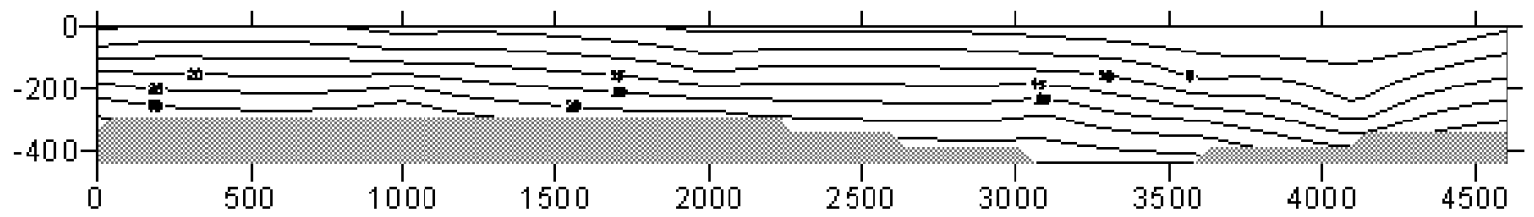

(b)

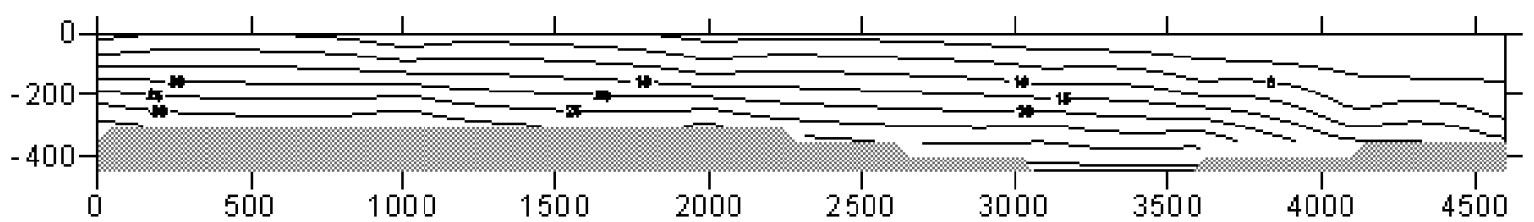

(c)

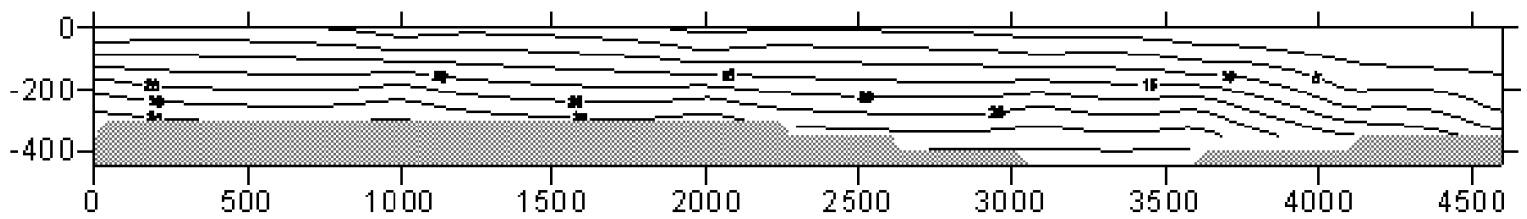

Sea Boundary

(d)

River Boundary

Figure 4. Longitudinal profiles of salinity upstream of the mouth of Strymon River measured on 31-08-2003 at:

(a) 11:00 am; (b) 13:00 pm; (c) 15:30 pm; and (d) 18:00 pm. The x-axis is in $\mathrm{m}$ and the $\mathrm{z}$-axis is in $\mathrm{cm}$. Isohaline labels are in psu.

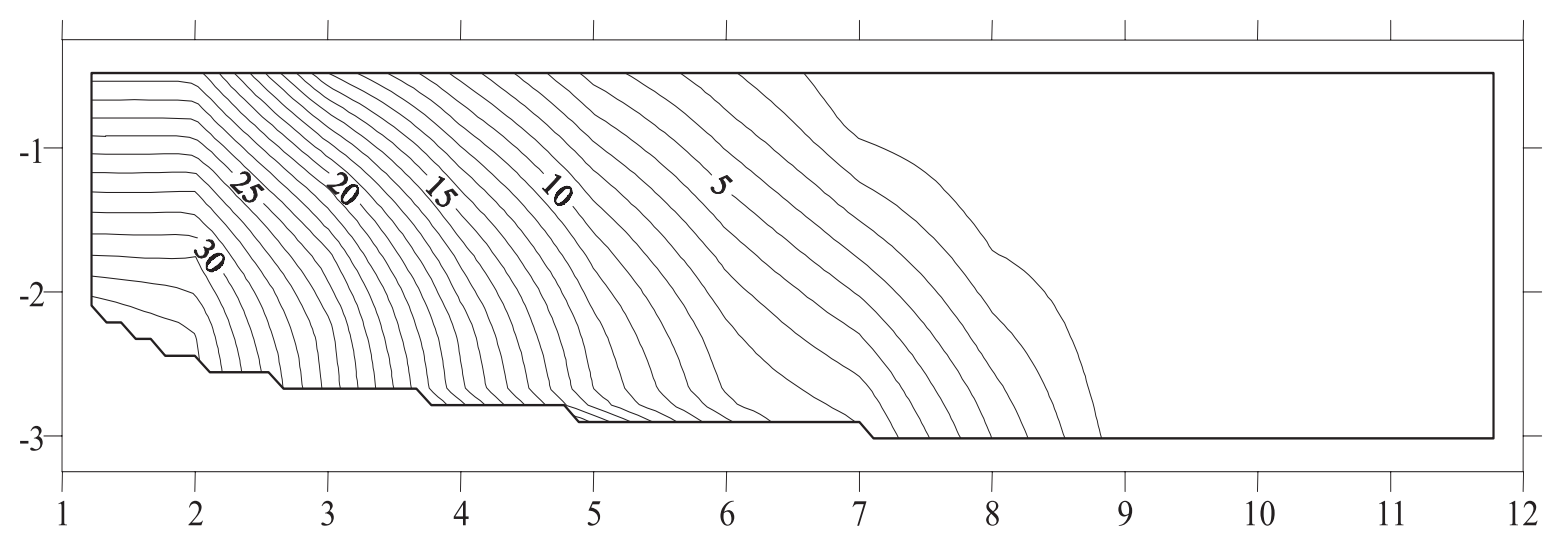

Figure 5. Longitudinal salinity distribution computed by the model under river discharge of $Q=15 \mathrm{~m}^{3} / \mathrm{s}$ at spring tide range $D E=45 \mathrm{~cm}$ and with Manning's roughness coefficient $n=0.050$. The lines are isohalines and the labels represent salinities in psu. The x-axis represents number of $\Delta x$ 's $(\Delta x=1000 \mathrm{~m})$ and the z-axis number of $\Delta z^{\prime} s(\Delta z=0.5 \mathrm{~m})$. 
(a)

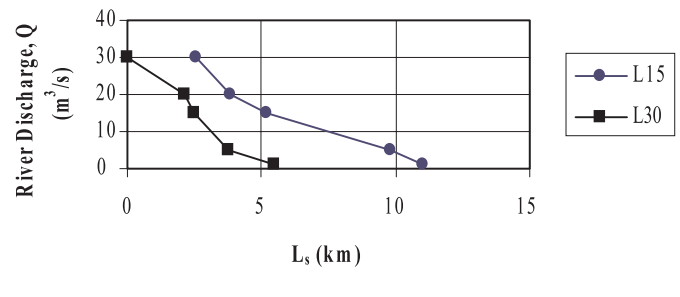

(b)

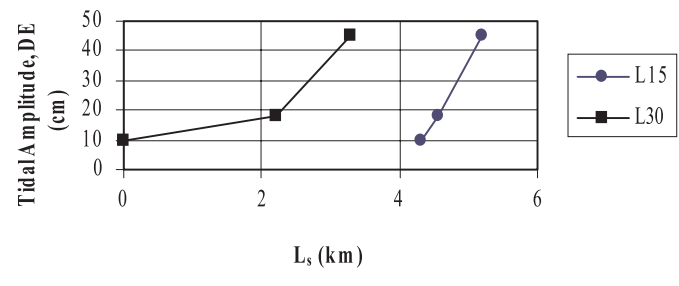

(c)

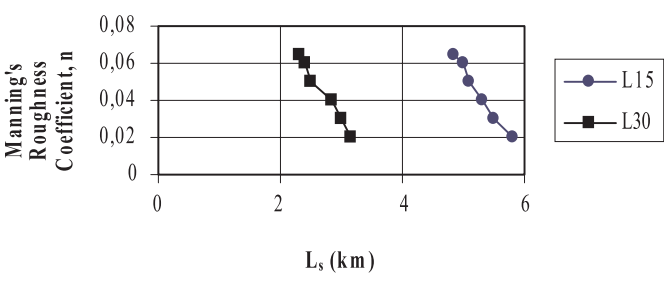

(d)

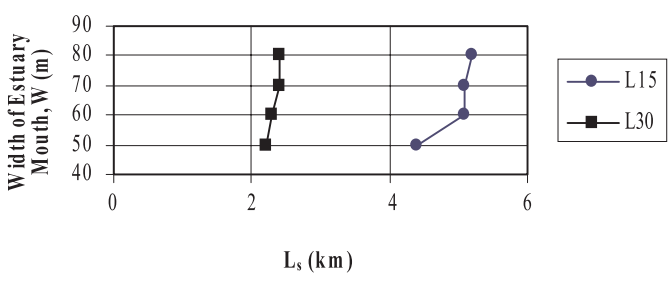

(e)

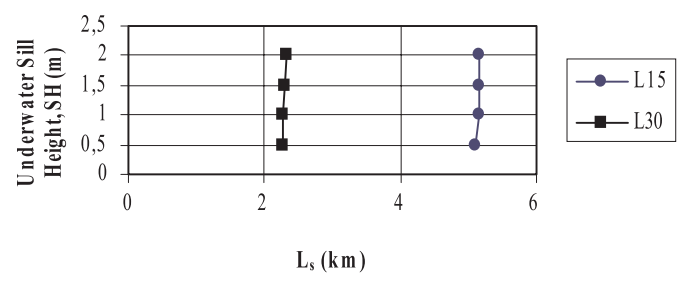

Figure 6. The relation of salinity intrusion length, $L_{S}$ to: (a) the river discharge $Q$; (b) the tidal amplitude $D E$; (c) the Manning's roughness coefficient $n$; (d) the width of the estuary mouth $W$; and (e) the underwater sill height at the estuary mouth $\mathrm{SH}$. 

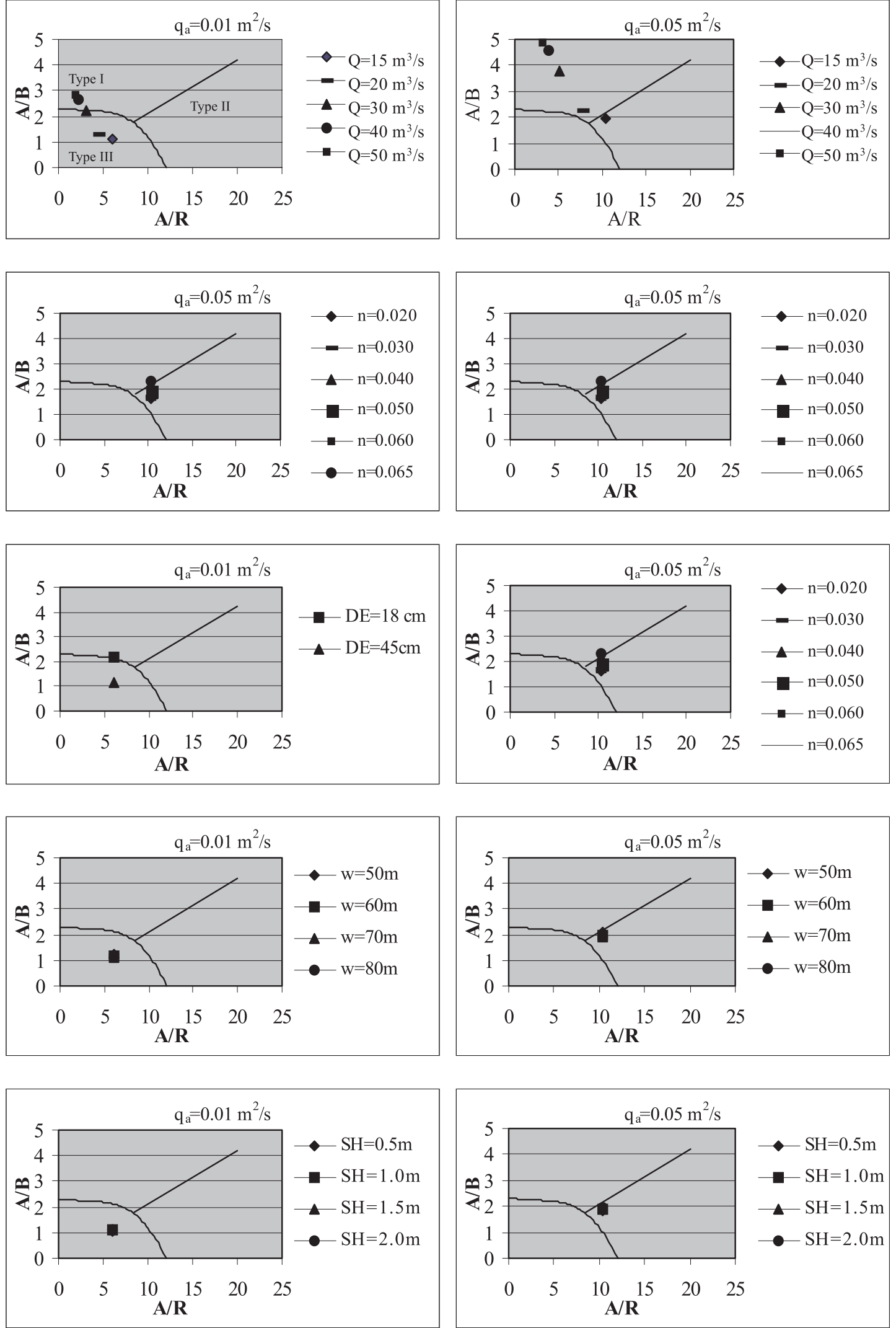

Figure 7. Diagrams of various conditions for two flowrates of air. 


\section{REFERENCES}

Abraham, G. and Burgh, P.v.d. (1964), Pneumatic reduction of salt intrusion through locks, Journal of Hydraulics Division, ASCE, 90(HY1), 83-119.

Blumberg, A.F. (1975), A numerical investigation into the dynamics of estuarine circulation, Technical Report 91, Chesapeake Bay Institute, The Johns Hopkins University, Baltimore.

Blumberg, A.F. (1977), Numerical model of estuarine circulation, Journal of Hydraulics Division, ASCE, 103(HY3), 295-310.

Hamilton, D.P., Chan, T., Robb, M.S., Pattiaratch, C.B. and Herzfeld M. (2001), The hydrology of the upper Swan River Estuary with focus on an artificial destratification trial, Hydrological Processes, 15, 2465-2480.

Haralambidou, K., Sylaios, G.K., Tsihrintzis, V.A. and Akratos, C. (2003a), A monitoring program for the study and management of the Strymon River Estuary, Proc. $9^{\text {th }}$ National Conference of the Hellenic Hydrotechnical Society, April 2-5, Thessaloniki, Greece, pp. 513-520 (in Greek).

Haralambidou, K., Sylaios, G.K. and Tsihrintzis, V.A. (2003b), Development of a numerical model to test alternatives to control saline wedge intrusion in an estuary, Proc. of the $X X X$ IAHR Congress, Theme A Coastal Environment: Processes and Integrated Management, August 24-29, Thessaloniki, Greece, pp. 107-114.

Haralambidou, K.I., Tsihrintzis, V.A. and Sylaios, G.K. (2003c), Control of saline wedge intrusion in the estuary of Strymonas River using an air curtain, Proc. of the $8^{\text {th }}$ Conference on Environmental Science and Technology, September 8-10, Porto Myrina Palace, Lemnos, Greece, Vol. A, pp. 302-309.

Haralambidou, K., Tsihrintzis, V.A., Sylaios, G.K. and Akratos, C. (2004). Seasonal and spatial characteristics of water quality in the estuary of Strymon River, Proc. of the International Conference on Protection and Restoration of the Environment VII, June 28-July 1, 2004, Mykonos, Greece, CD-Rom Section III (Surface Water Flow and Quality), \#3.

Hatzigiannakis, S. (2000), Hydrology of Strymon River, Report on the description of the coastal zone of Strymonikos and Ierissos Gulfs, (eds. E. Koutrakis and E. Lazaridou), Fisheries Research Institute NAGREF, Greek Biotope/Wetland Center, Nea Peramos, Kavala, Greece, pp. 5-32 (in Greek).

Kerstma, J., Kolkman, P.A., Regeling, H.J. and Venis, W.A. (1994), Water quality contol at ship locks, prevention on salt and fresh water exchange, Balkema, Netherlands.

Nakai, M. and Arita, M. (2002), An experimental study on the prevention of saline wedge intrusion by an air curtain in rivers, Journal of Hydraulic Research, 40(3), 333-339.

Parissis, A., Sylaios, G. and Tsihrintzis, V.A. (2001), A numerical model for the study of salt intrusion at Strymonas river mouth, Northern Greece, Proc. of $1^{\text {st }}$ International Conference on Ecological Protection of the Planet Earth, (eds. V.A. Tsihrintzis and P. Tsalides), June 5-8, Xanthi, Greece, pp. 281-288.

Raman, K. and Arbuckle, B. (1989), Long-term destratification in an Illinois Lake, Journal of American Water Works Association, 81, 66-71.

Smagorinsky, J. (1963), General circulation experiments with the primitive equations, Monthly Weather Review, 91, 99-164.

Sylaios, G. (1994), A numerical investigation into the dynamics of a partially-mixed estuary, Ph.D. Thesis, Dept. of Oceanography, Faculty of Science, University of Southampton, U.K.

Sylaios, G. (1999), Physical oceanography of Strymonikos Gulf and Gulf of Ierissos, Final Report on the description of the coastal zone of Strymonikos and Ierissos Gulfs, (eds. E. Koutrakis and E. Lazaridou), Fisheries Research Institute - NAGREF, Greek Biotope/Wetland Center, Nea Peramos, Kavala, Greece, pp. 119-218 (in Greek).

Tuin, H.v.d.T., Le, H.-T., Mikhailov, V., Roelfzema, A. and Volker, A. (1991), Guidelines on the study of seawater intrusion into rivers, UNESCO, France.

Vouvalides, K. (1998), Morphological, sedimentological and oceanographic processes and human impacts on the evolution of the Strymon River, Ph.D. Thesis, Dept. of Geology, Aristotle University of Thessaloniki, Greece (in Greek).

Yamada, T. (1975), The critical Richardson number and the ratio of the eddy transport coefficients obtained from a turbulence model, Journal of Atmospheric Science, 32, 926-933. 